\title{
Monitoring the cluster of high-risk mortality areas in the southwest of Spain
}

\author{
Maria Buxó-Pujolràs ${ }^{1,2,3}$, José Miguel Martínez ${ }^{1,4,5}$, Yutaka Yasui ${ }^{6}$, Carme Borrell ${ }^{5,7,8}$, Juan \\ Carlos Martín ${ }^{1,9}$, Montserrat Vergara ${ }^{1}$, Marta Cervantes ${ }^{10}$, Joan Benach ${ }^{1,5}$ \\ ${ }^{1}$ Health Inequalities Research Group - Employment Conditions Knowledge Network (GREDS-EMCONET), \\ Department of Political and Social Sciences, Universitat Pompeu Fabra, Barcelona, Spain; ${ }^{2}$ Epidemiology Unit \\ and Cancer Registry of Girona, Oncology Planning, Department of Health, Girona Biomedical Research \\ Institute, Girona, Spain; ${ }^{3}$ Department of Computer Science and Applied Mathematics, Universitat de Girona, \\ Girona, Spain; ${ }^{4}$ Center for Research in Occupational Health, Department of Experimental and Health Sciences, \\ Universitat Pompen Fabra, Barcelona, Spain; ${ }^{5}$ CIBER in Epidemiology and Public Health, Barcelona \\ Biomedical Research Park, Barcelona, Spain; ${ }^{6}$ Department of Public Health Sciences, School of Public Health, \\ University of Alberta, Edmonton, Canada; ${ }^{7}$ Health Service Information Systems, Barcelona Public Health \\ Agency, Barcelona, Spain; ${ }^{8}$ Department of Experimental and Health Sciences, Universitat Pompeu Fabra, \\ Barcelona, Spain; ${ }^{9}$ Biostatistics Unit, Department of Public Health, Universitat de Barcelona, Barcelona, Spain; \\ ${ }^{10}$ Cancer and Environmental Epidemiology Unit, National Centre for Epidemiology, Carlos III Institute of \\ Health, Madrid, Spain
}

\begin{abstract}
Inspired by a previous study showing a striking geographical mortality clustering, not attributable to chance, in the south-western region of Spain in 1987-1995, the authors have conducted an ecological study of time trends in all-cause mortality risk between 1987-1995 and 1996-2004 in 2,218 small areas of Spain. To identify high-risk areas, age-adjusted relative risks for each area, stratified by sex and time period, were computed using a Bayesian approach. Areas of high-risk in both periods, or in the second period only, were identified. Annual excess mortality and percentage of people living in these high-risk areas, again stratified by sex and time period, were estimated. The cluster of high mortality risk areas identified in the southwest of Spain during 1987-1995 persisted in the period 1996-2004 with an increase in the number of highrisk areas and in annual excess of mortality. These increases showed a gender difference, being more pronounced in women.
\end{abstract}

Keywords: geographical, mortality, clustering, time trends, high-risk, Spain.

\section{Introduction}

Descriptive studies of mortality in geographically small areas can provide important and useful information for public health purposes. Through these studies, it is possible to investigate inequalities in health between different areas, generate hypotheses about risk factors that may explain these inequalities, and establish public health policies in specific, high-mortality areas (Elliot et al., 2000; Elliott and Wartenberg, 2004). In addition, investigating the evolution of mortality over time adds information about risk trends and allows the simultaneous study of persistent pat-

Corresponding author:

Maria Buxó-Pujolràs

Department of Political and Social Sciences

Universitat Pompeu Fabra, Barcelona, Spain

Tel./Fax +3493542 2840;

E-mail: maria.buxo@upf.edu terns, highlighting unusual patterns and exploring potential risk factors in more detail (Richardson et al., 2006; Benach et al., 2007).

A number of studies focusing on small areas have found geographical inequalities in health and mortality (Pickle et al., 1999; Fitzpatrick et al., 2000; Vaneckova et al., 2010). While it is essential to evaluate whether or not observed patterns are likely to be due to chance, it is important to also quantify excess of mortality and analyse the temporal evolution of these spatial patterns. In the United States, a number of atlases and articles include comparisons of mortality patterns over time (Casper et al., 1995; Devesa et al., 1999; Ed Hsu et al., 2004; Rogerson et al., 2006; Chiu et al., 2008; Pickle, 2009). However, there are few European studies providing information on the geographical aggregation of high mortality risk areas that also investigate their temporal evolution (Benach et al., 2007; Exeter and Boyle 2007; Leyland et al., 2007; Bilancia and Fedespina, 2009). 
In Spain, various geographical mortality studies focusing on small areas show a consistent pattern of high mortality rates in the south, particularly in the Autonomous Community of Andalusia, a region with its own political institutions and legislative and executive powers (Benach et al., 2003a; López-Abente et al., 2006a). Significantly, one small-area study shows a striking geographical clustering of mortality not attributable to chance, affecting both men and women, in south-western Andalusia, specifically in the provinces of Huelva, Sevilla and Cádiz in the period 1987-1995 (Benach et al., 2004). To date, there has been no detailed research investigating the temporal evolution of mortality in these areas.

The objective of this article is to report an analysis of the temporal evolution of areas in Spain, identified as having a high mortality risk, between two time periods, i.e. 1987-1995 and 1996-2004, calculating the annual excess of mortality by gender. Our analysis focuses specifically on the provinces of Huelva, Sevilla and Cádiz in comparison with other areas of the Autonomous Community of Andalusia and the rest of Spain.

\section{Materials and methods}

\section{Study design}

We performed an ecological study of trends in allcause mortality risk between the periods 1987-1995 and 1996-2004. The units of analysis were the 2,218 small areas of Spain (municipalities or aggregates of municipalities) used in previous studies (Benach et al., 1997, 2003b, 2004).

\section{Mortality and population data}

Data on mortality for all causes of death were obtained from death certificates held by the Spanish National Institute of Statistics (INE). These data were provided by area of residence, age, sex and 3-year periods. In Spain, for confidentiality reasons, annual mortality data at the municipal level are available only for areas with populations of 10,000 people or more. However, information is also available for smaller areas (i.e. with 3,500-10,000 inhabitants) if the mortality data are aggregated for three or more years. Population data by sex, 5-year age group (e.g., 0-4, 5$9, \ldots, \geq 85)$, and municipality of residence were obtained from INE covering the national censuses of 1991 and 2001. The INE guarantees the privacy of the data providers (households, enterprises, administra- tions and other respondents) and the confidentiality of the information they provide requires that the information is used only for statistical purposes.

\section{Statistical analyses}

\section{Estimation of relative risks of mortality}

Separate calculations were performed for sex and time period. The relative risk (RR) of mortality in each of the 2,218 small areas studied was estimated from standardised mortality ratios (SMRs). The number of deaths in each of the areas was obtained by adding together all reported deaths. The whole population for each period was obtained by multiplying the middle year (1991 and 2001 census data, respectively) by the number of years that comprised the period according to previous research (Benach et al., 2004). We used age-specific mortality rates for Spain as reference rates for calculating the expected counts of death by sex for each small area and for each time period. These age-specific reference rates were obtained from a Poisson regression model with the generalised estimating equations (GEE) modification to account for potential within-area correlation of age-specific mortality (Liang and Zeger, 1986). To control the high variability of the SMR in areas with small population sizes, we estimated the relative risk of mortality by an empirical Bayes approach (Elliot et al., 1996). Specifically, we let $O_{i}$ and $E_{i}$, be the observed and expected counts, respectively, of deaths for each sex and for each time period (1987-1995; 1996-2004) of the $i^{\text {th }}$ area, where $i=1, \ldots, 2218$. We assumed a Poisson distribution of $\mathrm{O}_{i} \mid b_{i}$ with the following log-linear mean:

$$
\log \left(E\left[O_{i} \mid b_{i}\right]\right)=b_{i}+\log \left(E_{i}\right)
$$

where $b_{\mathrm{i}}$ represents the independent random effects following a normal distribution with the mean $=0$ and variance $=\sigma^{2}$. Once the empirical Bayes estimation of the random effects $b_{\mathrm{i}}$ had been obtained (Pinheiro and Bates, 1995), we computed the age-adjusted relative risk for the $i^{\text {th }}$ area, $\theta_{i}$, from:

$$
\theta_{i}=e^{b i}
$$

\section{Determination of high-risk areas}

To identify high-risk areas, we used the following procedure. For each area, we tested a null hypothesis of $b_{i}$ being equal to 0 (Booth and Hobert, 1998). If the 
departure from the null value was statistically significant (at the $5 \%$ level) and the empirical Bayes estimate of relative risk was above 1 , the area was considered to have a statistically significant, elevated risk. Within the set of all such elevated-risk areas, we classified those with empirical Bayes estimates of relative risk above the median as high-risk areas.

\section{Temporal evolution of high-risk areas}

The following steps were followed in order to study the temporal evolution of the identified high-risk areas. Firstly, for each sex, the small areas deemed to be of high-risk in both time periods [both periods] or in the second period only (1996-2004) [only last period] were represented on a map. Secondly, to facilitate a more detailed study of geographical differences of the high-risk areas in the Huelva, Sevilla and Cádiz provinces, three geographical zones were defined:

(i) the provinces of Huelva, Sevilla and Cádiz (here termed HSC) comprised of 149 small areas;

(ii) the Autonomous Community of Andalusia, excluding HSC, comprised of 256 small areas (here termed AND); and

(iii) Spain, excluding the AND, comprised of the 1,813 remaining small areas in the country (here termed ESP) (Fig. 1).

For each of the three geographical zones, stratified by sex and time period, we calculated the annual excess mortality in each period, defined as the difference between the observed and expected deaths divided by 9 , and quantified the percentage of the population living in the high-risk areas within each geo- graphical zone (HSC, AND, ESP). The statistical analyses were carried out using SPSS 9.0 (SPSS Inc., 1998, Chicago, IL, USA), SAS 8 (SAS Institute Inc., Ver. 8, 2000, Cary, NC, USA). Graphic design and image management were carried out using Excel 97 (Microsoft Excel, 2003) and MapInfo 7.0 software packages (Corporation Mapinfo 7 ed., 2002, New York, USA).

\section{Results}

Between 1987 and 1995, the total number of deaths in Spain was 1,568,152 among men and 1,389,889 among women. These numbers increased in the period 1996- 2004 to $1,704,811$ and 1,543,094, respectively. For men, the high-risk areas of the period 1987-1995 represented $11.4 \%(\mathrm{n}=252)$ of all small areas in Spain, whereas in the period 1996-2004 the figure was $10.7 \%(\mathrm{n}=238)$. For women, the percentage of highrisk areas corresponding to the first and second periods were $12.4 \%(\mathrm{n}=274)$ and $13.4 \%(\mathrm{n}=297)$, respectively. Thus, there was an increase among women and a reduction among men in the variability in mortality in the high-risk areas. For men, although the median of estimated RR was similar for both periods and across the three geographical zones, the maximum value in HSC only increased, from 1.49 during 1987-1995 to 1.63 during 1996-2000. In women, the estimated RR (median, maximum and minimum) increased in the second period for all zones, being more pronounced in HSC.

Fig. 2 and Fig. 3 show, for each sex, the areas that evolved to higher mortality levels than Spain overall

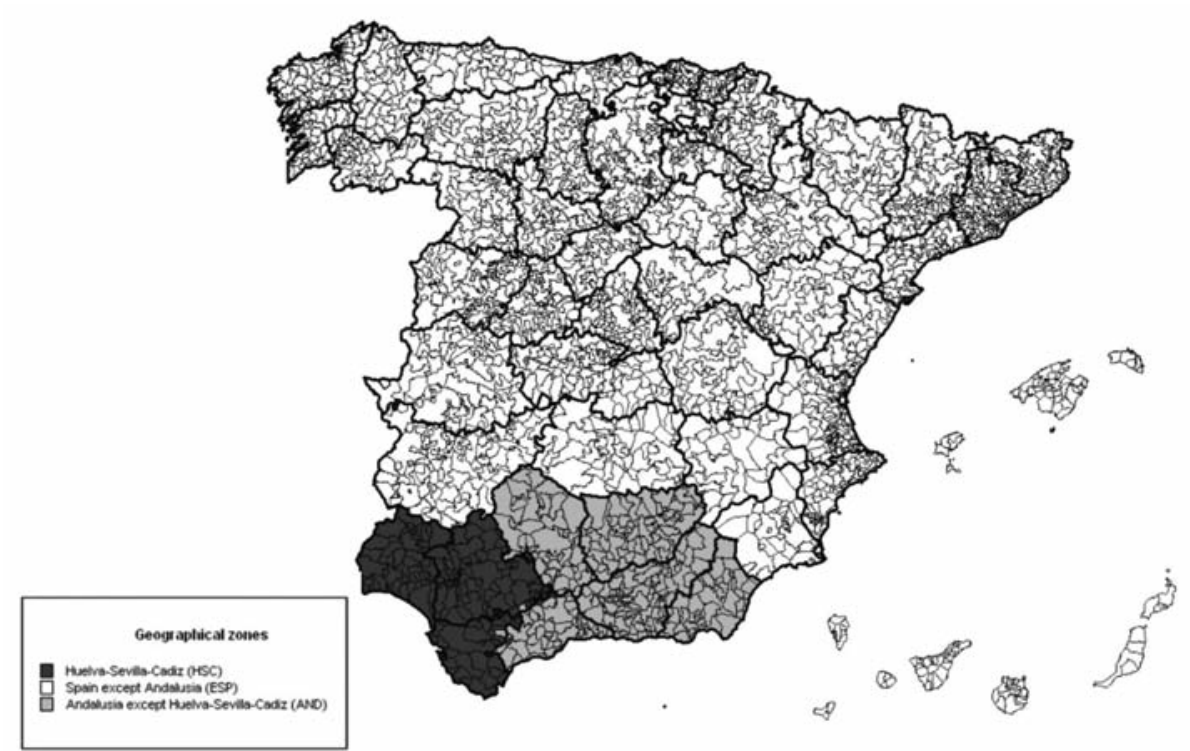

Fig. 1. Geographical zones of Spain used for the current analysis. 


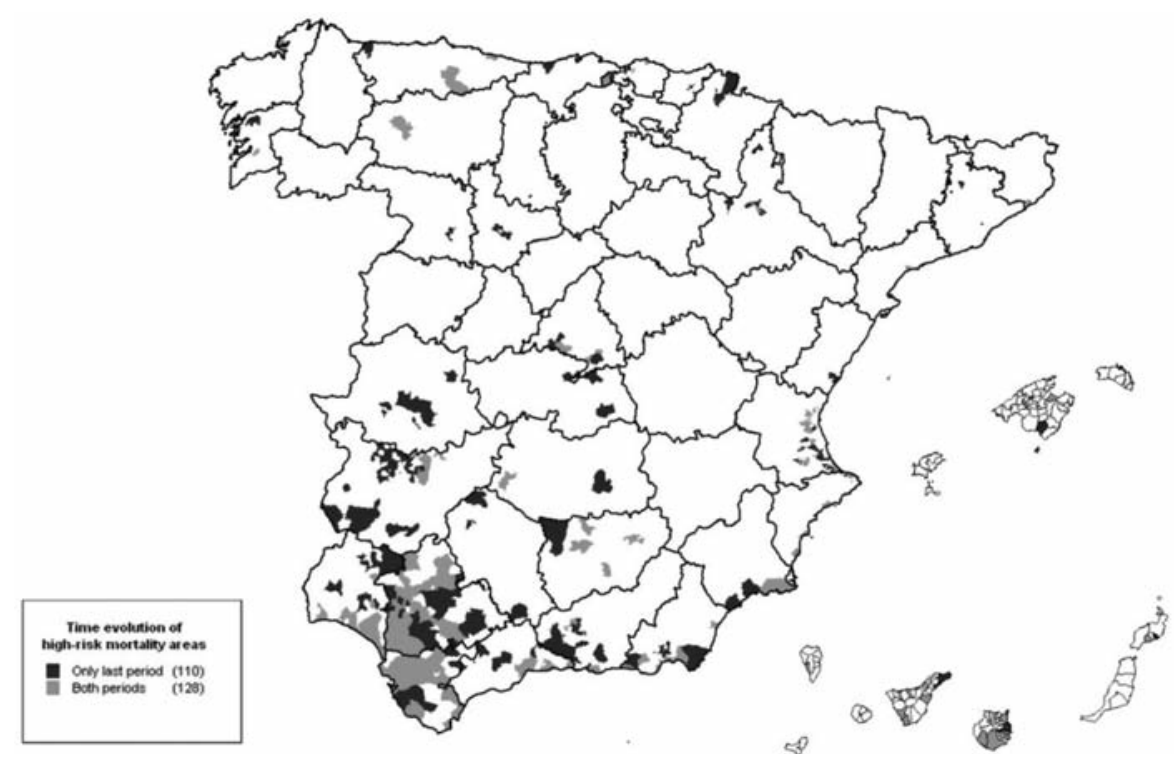

Fig. 2. High mortality risk areas in both periods (1987-1995; 1996-2004) and in the second period only (1996-2004) among men.

during the period studied. These areas were either not at high risk in 1987-1995 but became so by 19962004, or they were at high risk in both periods. The maps show more clearly, both for men and women, a clear aggregation of high-risk areas in HSC due to the presence of the same high-risk areas in both periods and the emergence of new areas of high-risk in 19962004.

When we analysed the situation in HSC in comparison with the rest of Andalusia, and in comparison of the rest of Spain (except for Andalusia), we observed differences in the temporal evolution of the high-risk areas. In men, the number of high-risk areas in HSC and in the rest of Andalusia increased slightly from
$49.0 \%(\mathrm{n}=73)$ to $51.7 \%(\mathrm{n}=77)$ and from $16.8 \%(\mathrm{n}$ $=43)$ to $18.0 \%(n=46)$, respectively. In Spain as a whole (except for Andalusia), however, we found that a decline had occurred. The number of high-risk areas fell to $6.3 \%(\mathrm{n}=115)$ for $1996-2004$, from $7.5 \%(\mathrm{n}=$ $136)$ in the period 1987-1995. In women, a considerable increase in mortality was found both in HSC and in the rest of Andalusia. In HSC, the percentage of high-risk areas was $41.6 \%(n=62)$ for the period $1987-1995$ and $56.4 \%(\mathrm{n}=84)$ for 1996-2004. In the rest of Andalusia, the percentages were $20.7 \%$ ( $\mathrm{n}=$ $53)$ and $27.0 \%(\mathrm{n}=69)$, respectively. In Spain as a whole (except for Andalusia), however, there was a slight decline in the percentage of high-risk areas, with

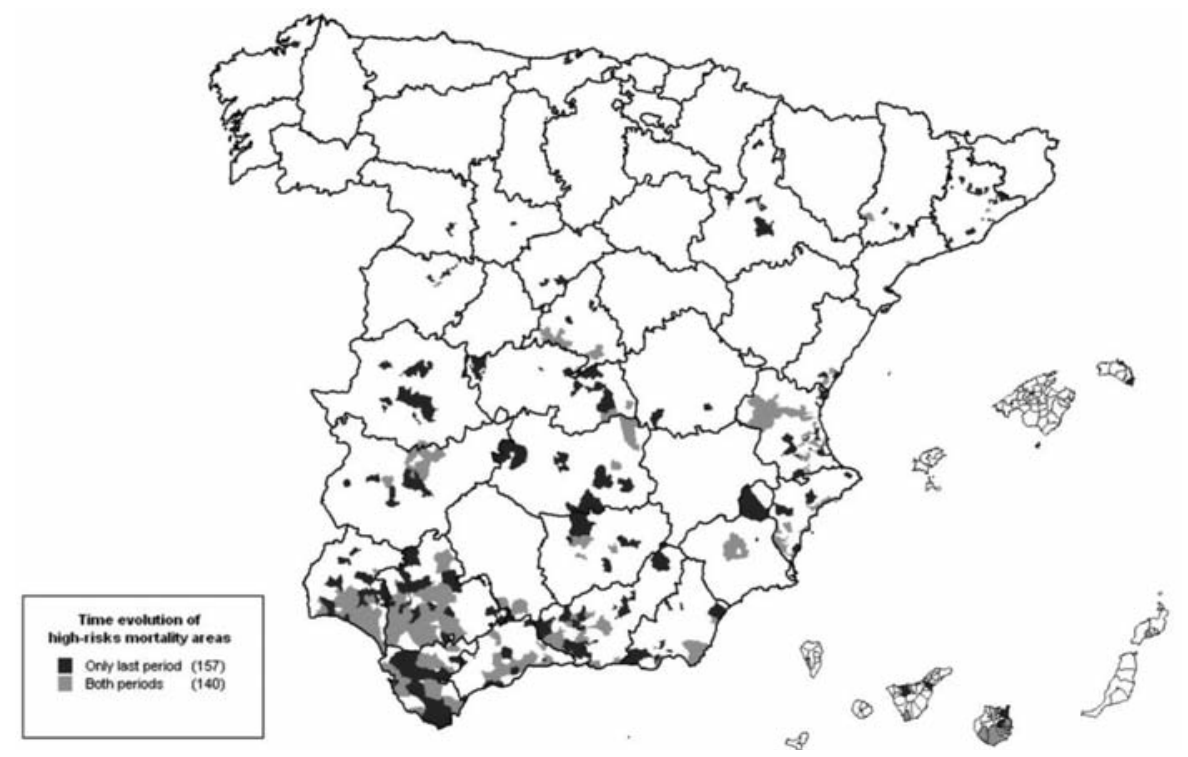

Fig. 3. High mortality risk areas in both periods (1987-1995; 1996-2004) and in the second period only (1996-2004) among women. 
$8.8 \%(\mathrm{n}=159)$ in the first period and $7.9 \%(\mathrm{n}=144)$ in the second period.

Table 1 shows the annual excess mortality and the percentage of population at risk by sex, time period, and geographical zone. For men, unlike AND and Spain overall, there was an increase in the annual excess mortality in HSC. The increase in mortality in HSC between the two periods was $10.6 \%(1,945$ deaths for 1987-1995 and 2,151 deaths for 19962004). However, in women there was an increase in the annual excess of deaths for all geographical zones. This was particularly marked in HSC, where there was an increase of almost $70 \%$, from 968 deaths for 1987 1995 to 1,637 deaths for 1996-2004. In men, the percentages of the population living in the high-risk areas during 1987-1995 and 1996-2004, only increased slightly in HSC (from $73.8 \%$ to $78.2 \%$ ), whereas it decreased in the rest of Andalusia (from 39.7\% to $33.8 \%$ ), and in Spain overall (from 9.5\% to 8.3\%). In contrast, mortality increased in the female population living in high-risk areas among three zones surveyed with the increase being more pronounced in HSC, from $43.9 \%$ during $1987-1995$ to $60.5 \%$ during 1996-2004.

\section{Discussion}

This study is, to our knowledge, one of the first to analyse small-area mortality risk over time in southern Europe. It estimates the annual excess of mortality and describes in detail the evolution of a striking geographical mortality cluster in Spain. Specifically, this study provides updated and more detailed information about the clustering in areas with the highest mortality in HSC in the south-western region of Spain during 1987-1995 (Benach et al., 2004). The results also show that the cluster of high-risk areas corresponding to this period in these provinces, both for men and women, persisted into the period 1996-2004. In addition, an increase in the inequality of mortality between zones and sexes was observed. Women experienced a more negative trajectory, showing a considerable increase in the number of high-risk areas, both in HSC and in the rest of Andalusia. In men, although there was a slight increase in the number of high-risk areas between the two periods studied, both in HSC and in the rest of Andalusia, an excess of mortality was only observed in HSC. On the other hand, for women, an annual excess of deaths was observed, both in HSC and in the rest of Andalusia.

The mortality data used in the present study constitute an exhaustive source of information, representative of both local and national levels. Continuous data have been compiled over long periods of time, and fulfil markers of standardisation and quality allowing proper monitoring of the health of the people living in small geographical areas (Percy et al., 1981). The small areas analysed in this study were constructed to have the maximum level of within-area homogeneity with respect to social factors, as well as an appropriately similar population size in each area (Benach et al., 1997). Applying geographical information system (GIS) techniques and a method based on three main criteria, i.e. contiguity of small areas, similarity of socioeconomic indicators and a minimum population size, made it possible to reduce the 8,077 municipalities to 2,200 geographical zones with at least 3,500 inhabitants each (Navarro and Benach 1996; Benach 1998). The aggregation of areas took into account the geographical contiguity and similarity in relation to social homogeneity between areas. Taken together, these factors enabled us to conduct the first nation-

Table 1. Distribution of relative risk of mortality, annual excess mortality and percentage of populations living in the high-risk areas by time period, geographical zone and sex.

\begin{tabular}{|c|c|c|c|c|c|c|c|c|}
\hline & \multirow[t]{2}{*}{ Geographical zone } & \multicolumn{2}{|c|}{$\begin{array}{c}\text { Relative risk } \\
\text { (median; min; max) }\end{array}$} & \multicolumn{3}{|c|}{ Annual excess mortality } & \multicolumn{2}{|c|}{$\begin{array}{l}\text { Population living in } \\
\text { high-risk areas* }(\%)\end{array}$} \\
\hline & & $1987-1995$ & $1996-2004$ & $1987-1995$ & $1996-2004$ & $\%$ change & $1987-1995$ & 1996-2004 \\
\hline \multirow[t]{3}{*}{ Men } & HSC & $1.23 ; 1.16 ; 1.49$ & $1.22 ; 1.16 ; 1.63$ & 1,945 & 2,151 & 10.6 & 73.8 & 78.2 \\
\hline & Andalusia excluding HSC & $1.22 ; 1.16 ; 1.51$ & $1.21 ; 1.16 ; 1.49$ & 1,269 & 1,193 & -6.0 & 39.7 & 33.8 \\
\hline & Spain excluding Andalusia & $1.22 ; 1.16 ; 2.45$ & $1.20 ; 1.16 ; 1.73$ & 2,806 & 2,534 & -9.7 & 9.4 & 8.3 \\
\hline \multirow[t]{3}{*}{ Women } & HSC & $1.22 ; 1.17 ; 1.39$ & $1.27 ; 1.18 ; 2.08$ & 968 & 1,637 & 69.0 & 43.9 & 60.5 \\
\hline & Andalusia excluding HSC & $1.23 ; 1.17 ; 1.42$ & $1.27 ; 1.19 ; 1.62$ & 906 & 1,300 & 43.6 & 32.5 & 38.6 \\
\hline & Spain excluding Andalusia & $1.22 ; 1.17 ; 1.70$ & $1.25 ; 1.18 ; 1.88$ & 2,101 & 2,519 & 19.9 & 7.3 & 7.7 \\
\hline
\end{tabular}

*National census returns for the years 1991 and 2001 were used to estimate the population at risk for the periods 1987-1995 and 1996-2004, respectively. 
based, small-area analyses in Spain.

It is difficult to explain the high mortality observed in this area of southwest Spain, since risk areas are characterised by a heterogeneous set of social determinants and risk and protective factors that can influence the mortality profile and health status in different ways, and the effects of which are difficult to distinguish. The region studied corresponds, in qualitative terms, with one of the most deprived and contaminated areas of the country; when the mortality cluster was first detected it was not identified as the result of a single cause or determinant. Rather, a more plausible explanation for the high rates of mortality observed was the interrelation of social, environmental and occupational determinants (Benach et al., 2004). Although the exact causes of this high mortality risk remain unknown, data published in the last five years indicate that the previous hypothesis is valid.

With regard to the socioeconomic environment, according to the social yearbook of Spain 2004, the provinces of the south and southwest of Spain had the lowest levels of available income per capita. In particular, the HSC provinces of registered income values approximately $18 \%$ lower than the Spanish average (Spanish Annual Social Report, 2004). Similarly, using data from the 2001 national census, one also observes that these three provinces show the highest rates of unemployment; $23.7 \%, 24.2 \%$ and $29.3 \%$, respectively. These unemployment levels are well above both the Spanish average (14.2\%) and the Andalusian average $(21.2 \%)$ (Population and Housing Census, 2009). Regarding environmental determinants, the precise degree of exposure to risk factors among the population remains unknown at the moment for Spain as a whole. Nevertheless, by means of indirect indicators, it is possible to determine the geographical distribution of industrial contamination, including specific pollutants, which would imply increased exposure for people living and working in these areas. It has been observed that the types of industrial plants situated in the Autonomous Community of Andalusia tend to discharge more pollutants into the air and water as compared to the rest Spain (García-Perez et al., 2007). On the other hand, an inventory of atmospheric polluting emissions, carried out in the Autonomous Community of Andalusia in 2005 and some specific environmental and toxicological sanitary studies conducted in recent years, have detected two specific south-western areas (Ría de Huelva and Campo de Gibraltar) that consistently present the highest levels of sulphur dioxide, nitrogen oxides, benzene, lead as well as particulate matter of $<10 \mu \mathrm{m}$ (PM10) (Ría de Huelva) and methane (Campo de Gibraltar) (Andalusian Atmospheric Emissions Inventory 2005, 2009; Environmental Diagnosis in Campo Gibraltar, 2009; Sanitary and Environmental Diagnosis in Ría Huelva, 2009). These substances have been associated with increased mortality overall, with specific causes of death (cardiovascular or respiratory), development of various types of cancers (skin, lung, leukaemia, bladder, kidney) or disturbances in the nervous, reproductive and immunological systems (Bertollini et al., 1996; Agency of Toxic Substances and Disease Registry, 2009; International Agency for Research on Cancer, 2009a,b). In addition, high levels of mortality by different specific-causes of death, such as lung cancer, prostate cancer, heart disease or atherosclerosis (Benach et al., 2001; Municipal Mortality in the Province of Cádiz, 2009; Sanitary and Environmental Diagnosis in Ría Huelva, 2009), and a greater risk of premature mortality in both sexes (Cruz and Almisas, 2009) have been found in these two areas when compared to the whole of Andalusia or to Spain as a whole. At the workplace level, the evidence remains much more limited. However, a recent study among workers of the chemical and metallurgical industries in the eight Andalusian provinces suggests that working in the vicinity of the Huelva City industrial chemicals complex (Polo Químico de Huelva) contributes to the accumulation of uranium-238 in the bodies of those who work there (Alguacil et al., 2009).

This study does not explain the causes for the differences in mortality found between men and women. Cause-specific and sex-specific mortality studies could help to clarify these disparities. For example, the geographical pattern of mortality shows that lung cancer and bladder cancer in men remain at the highest levels in south-western Spain (Benach et al., 2001; LópezAbente et al., 2006b); these two diseases are generally associated with occupational exposure (Driscoll et al., 2004; Siemiatycki et al., 2004) and socioeconomic factors (Mackenbach et al., 2008; Marletti et al., 2011). With respect to women, the spatial analysis of breast cancer mortality shows high levels of the disease in south-western Spain. This form of cancer has typically been linked to high socioeconomic status (Kogevinas et al., 1997; Strand et al., 2007). However, this region is among the poorest in Spain, suggesting that other determinants are affecting breast cancer mortality rates in these areas. Recent studies have strengthened the evidence showing that environmental exposures (including chemical and other occupational risk factors) play a role in breast cancer risk and could therefore, at least partially, explain the high mortality 
in these areas (Brody et al., 2007).

Due to the magnitude of the problem and the complexity of its potential causes, it is essential to carry out specific and multidisciplinary studies, incorporating community members, policy makers, practitioners, and other stakeholders when attempting to approach this public health problem (Leung et al., 2004). Future research efforts might focus on co-morbidities or environmental and occupational risk factors, including spatially distributed variables such as exposure to pollutants. In addition, it will be necessary to compare these results with other health indicators such as incidence (e.g. mapping childhood cancer or occupational cancers) or quality of life indicators designed to quantify the burden of disease, (e.g. estimating the disability-adjusted life years (DALYs World Bank, 1993; Murray and Lopez, 1996; Rubinstein et al., 2010). However, this type of information is still not available in Spain neither at the provincial nor the municipal level.

\section{Conclusion}

This study confirms that an important public health problem persists in south-western Spain, carrying an increased risk of mortality that has intensified in women over time. Although the mapping of high-risk mortality areas cannot pinpoint causative or mediating factors for this problem, or identify the particular mechanisms responsible for these inequalities, it can be used to identify target areas for screening as well as areas for future research into both primary and secondary prevention. It should be noted that mortality represents an extreme event likely to be linked to several environmental, socioeconomic and occupational exposures. The results obtained by this study strongly indicate an important public health problem, with serious effects. In response to these issues, public administrative bodies should urgently adopt a variety of measures. First, the governments should allocate more public health resources for the diagnosis and improvement of evaluations of the situation with scientific studies, including specific studies in areas with the highest mortality levels or multidisciplinary investigations on the interactions between social, occupational and environmental conditions and risk factors. Participatory strategies that empower communities can increase both the quality of research and knowledge translation from research to effective interventions to alleviate the problems identified. Secondly, a programme of monitoring and detection should be consolidated to permit existing problems such as can- cer, asthma, allergies and other environmental and occupational diseases to be monitored systematically.

\section{Acknowledgements}

The study was partially funded by the Ministry of Health, Instituto de Salud Carlos III (FIS 07/0285)

\section{References}

Alguacil J, Capelo R, González M, García T, Gómez-Ariza JL, Anglada J, Gómez MT, De la Rosa J, Pereira A, 2009. Dosis interna acumulada de uranio en trabajadores que realizan su actividad en las proximidades de la balsa de fosfoyesos de Huelva. In XIII Congreso SESPAS, Sevilla Spain.

Benach J, 1998. Social inequalities in mortality in small areas in Spain. PhD thesis Johns Hopkins University, Department of Sociology, Baltimore, MD, USA.

Benach J, García MD, Donado-Campos J, 1997. GIS for mapping mortality inequalities in Spain and its socioeconomic determinants, constructing regions using small areas. Proceedings of the International Symposium on Computer Mapping in the Epidemiology and Environmental Health, Tampa, FL, pp. 314-322.

Benach J, Martínez JM, Borrell C, Pasarín MI, Yasui Y, Vergara M, Buxo M, Muntaner C, Daponte A, Ocaña R, 2007. Estudio geográfico de la mortalidad en España: Análisis de tendencias temporales en municipios o agregados de municipios. Fundación BBVA, 93 pp.

Benach J, Yasui Y, Borrell C, Pasarín MI, Martínez JM, Daponte A, 2003b. The public health burden of material deprivation: excess mortality in leading causes of death in Spain. Prev Med 36, 300-308.

Benach J, Yasui Y, Borrell C, Rosa E, Pasarín MI, Benach N, Español E, Martínez JM, Daponte A, 2001. Atlas de mortalidad en áreas pequeñas en España (1978-1995). UPF/MSD, $114 \mathrm{pp}$.

Benach J, Yasui Y, Borrell C, Rosa E, Pasarín MI, Benach N, Español E, Martínez JM, Daponte A, 2003a. Examining geographical patterns of mortality: the atlas of mortality in small areas in Spain (1987-1995). Eur J Public Health 13, 115-123. Benach J, Yasui Y, Martínez JM, Borrell C, Pasarín MI, Daponte A, 2004. The geography of the highest mortality areas in Spain, a striking cluster in the southwestern region of the country. Occup Environ Med 61, 280-281.

Bertollini R, Lebowitz MD, Saracci R, Savitz DA, 1996. Environmental epidemiology: exposure and disease. CRC Press, 256 pp.

Bilancia M, Fedespina A, 2009. Geographical clustering of lung cancer in the province of Lecce, Italy, 1992-2001. Int J Health Geogr, 8-40.

Booth JG, Hobert JP, 1998. Standard errors of prediction in gen- 
eralized linear mixed models. J Am Stat Assoc 93, 262-272.

Brody JG, Moysich KB, Humblet O, Attfild KR, Beehler GP, Rudel RA, 2007. Environmental pollutants and breast cancer, epidemiologic studies. Cancer 109, 2667-2711.

Casper ML, Wings S, Anda RF, Knowles M, Pollard Ra, 1995. The shift stroke belt. Changes in the geographical pattern of stroke mortality in the United States, 1962 to 1988. Stroke 26, 755-760.

Centro Superior de Investigaciones Científicas. Ministerio de Ciencia e Innovación, 2009. Environmenal Diagnosis in Campo Gibraltar [Diagnóstico sobre la situación ambiental del entorno del campo de Gibraltar. Available at: http://www.csic.es/gibraltar.do] (accessed on May 2009).

Centro Superior de Investigaciones Científicas. Ministerio de Ciencia e Innovación, 2009. Sanitary and Environmental Diagnosis in Ría Huelva [Informes del estudio sobre el diagnóstico ambiental y sanitario de la Ría de Huelva]. Available at: http://www.csic.es/ria_huelva.do (accessed on May 2009).

Chiu YW, Wang MQ, Chuang HY, Hsu CE, Nkhoma ET, 2008. A new application of spatiotemporal analysis for detecting demographic variations in AIDS mortality, an example from Florida. Kaohsiung, Taiwan. J Med Sci 24, 568-76.

Consejería de Salud, Junta de Andalucía, 2009. Municipal mortality in the Province of Cádiz [Estudio sobre la mortalidad por municipios en la provincia de Cádiz y estudio sobre la situación de salud en la provincia de Cádiz]. Available at: http://www.juntadeandalucia.es/salud/export/sites/csalud/ galerias/documentos/p_4_p_1_vigilancia_de_la_salud/mortalidad_salud_cadiz.pdf (accessed on October 2009).

Consejería de Medio Ambiente. Junta de Andalucía, 2009. Andalusian Atmospheric Emissions Inventory 2005. Available at: http://www.juntadeandalucia.es/medioambiente/site/web/ menuitem.a5664a214f73c3df81d8899661525ea0/?vgnextoid=bb6d2ec12b5a 8110 VgnVCM1000000624e50aRCRD\& vgnextchannel=3259b19c7acf2010VgnVCM1000001625e50 aRCRD\&lr=lang_es (accessed on July 2009).

Cruz C, Almisas M, 2009. Epidemiological analysis of mortality by causes in Bahía de Algeciras, Spain (2001-2005). Gac Sanit 23, 388-395.

Devesa SS, Grauman DJ, Blot WJ, Fraumeni JF Jr. 1999. Cancer surveillance series: changing geographical patterns of lung cancer mortality in the United States, 1950 through 1994. J Natl Cancer Inst 91, 1040-1050.

Driscoll T, Steenland K, Prüss-Üstün A, Nelson D, Leigh J, 2004. Occupational carcinogens: assessing the environmental burden of disease at national and local levels. Geneva, World Health Organization, Environmental burden of disease series No. 6.

Ed Hsu C, Jacobson H, Soto Mas F, 2004. Evaluating the disparity of female breast cancer mortality among racial groups a spatiotemporal analysis. Int J Health Geogr 3, 4.

Elliot P, Cuzick J, English D, Stern R, 1996. Geographical and environmental epidemiology. Methods for small-area studies. Oxford University Press, 404 pp.

Elliot P, Wakefield J, Best N, Briggs D, 2000. Spatial and applications. Oxford University Press, 475 pp.

Elliott P, Wartenberg D, 2004. Spatial epidemiology, current approaches and future challenges. Environ Health Perspect 112, 998-1006.

Exeter DJ, Boyle PJ, 2007. Does young adult suicide cluster geographically in Scotland? J Epidemiol Community Health 61, 731-736

Fitzpatrick J, Griffiths C, Kelleher M, 2000. Geographical inequalities in mortality in the United Kingdom during the 1990s. London, UK. ONS Health Statistics Quarterly 7, 1831.

García-Pérez J, Boldo E, Ramis R, Pollán M, Pérez-Gómez B, Aragonés N, López-Abente G, 2007. Description of industrial pollution in Spain. BMC Public Health 21, 7-40.

Instituto Nacional de Estadística, 2009. Population and Health Census [Cifras de Población y Censos Demográficos]. Available at: http://www.ine.es/inebmenu/mnu_cifraspob.htm (accessed on August 2009).

International Agency for Research on Cancer, 2009a. Monographs on the evaluation of carcinogenic risks to humans. Available at: http://monographs.iarc.fr/ENG/ Monographs/PDFs /index.php (accessed on August 2009).

International Agency for Research on Cancer, 2009b. World cancer report. Available at: http://www.iarc.fr/en/publications/pdfs-online/wcr/2008/index.php (accessed on August 2009).

Kogevinas M, Pearce N, Susser M, Boffetta P, 1997. Social inequalities and cancer, IARC Scientific Publications No. 138, 397 pp.

Leung MW, Yen IH, Minkler M, 2004. Community based participatory research: a promising approach for increasing epidemiology's relevance in the $21^{\text {st }}$ century. Int J Epidemiol 33, 499-506.

Leyland AH, Dundas R, McLoone P, Boddy FA, 2007. Causespecific inequalities in mortality in Scotland: two decades of change. A population-based study. BMC Public Health 24, 7172.

Liang KY, Zeger SL, 1986. Longitudinal data analysis using generalized linear models. Biometrika 73, 13-22.

López-Abente G, Ramis R, Pollán M, Aragonés N, PérezGómez B, Gómez-Barroso D, Carrasco JM, Lope V, GarcíaPérez J, Boldo E, García-Mendizabal MJ, 2006a. Atlas municipal de mortalidad por cáncer en España 1989-1998. Instituto de Salud Carlos III SCII Área de Epidemiología Ambiental y Cáncer del Centro Nacional de Epidemiología, 152 pp.

López-Abente G, Aragones N, Ramis R, Hernandez-Barrera V, Perez-Gomez B, Escolar-Pujolar A, Pollan M, 2006b. Municipal distribution of bladder cancer mortality in Spain: 
possible role of mining and industry. BMC Public Health 27, 6-17.

Mackenbach JP, Stirbu I, Roskam AJ, Schaap MM, Menvielle G, Leinsalu M, Kunst AE, European Union Working Group on Socioeconomic Inequalities in Health, 2008. Socioeconomic inequalities in health in 22 European countries. N Engl J Med 358, 2468-2481.

Marletti F, Galassi C, Spadea T, 2011. The socioeconomic determinants of cancer. Environ Health 10, S7.

Murray CJL, Lopez AD, 1996. Alternative visions of the future: projecting mortality and disability, 1990-2020. In: The Global Burden of Disease. (CJL Murray and AD Lopez eds), Vol. 1, Global Burden of Disease and Injury Series, Cambridge, Harvard University Press.

Navarro V, Benach J, 1996. Desigualdades sociales en salud en España. Madrid, Ministerio de sanidad y consumo.

Percy C, Stanek E, Gloeckler L, 1981. Accuracy of cancer death certificates and its effect on cancer mortality statistics. Am J Public Health 71, 242-250.

Pickle LW, 2009. A history and critique of U.S. mortality atlases. Spat Spattemporal Epidemiol 1, 3-17.

Pickle LW, Mungiole M, Jones GK, White AA, 1999. Exploring spatial patterns of mortality: the new atlas of United States mortality. Stat Med 18, 3211-3220.

Pinheiro JC, Bates DM, 1995. Approximations to the log-likelihood function in the nonlinear mixed-effects model. J Comput Graph Stat 4, 12-35.

Public Health Statements, 2009. Agency for Toxic Substances \& Disease Registry. Available at: http://www.atsdr.cdc.gov /phshome.html (accessed on August 2009).
Richardson S, Abellan JJ, Best N, 2006. Bayesian spatio-temporal analysis of joint patterns of male and female lung cancer risks in Yorkshire, UK. Stat Methods Med Res 15, 385-407.

Rogerson PA, Sinha G, Han D, 2006. Recent changes in the spatial pattern of prostate cancer in the US. Am J Prev Med 30, S50-S59.

Rubinstein A, Colantonio L, Bardach A, Caporale J, Marti SG, Kopitowski K, Alcaraz A, Gibbons L, Augustovski F, PichónRivière A, 2010. Estimation of the burden of cardiovascular disease attributable to modifiable risk factors and cost-effectiveness analysis of preventative interventions to reduce this burden in Argentina. BMC Public Health, 10, 627.

Siemiatycki J, Richardson L, Straif K, Latreille R, Campbell S, Rousseau MC, Boffeta P, 2004. Listing occupational carcinogens. Environ Health Perspect 112, 1447-1459.

Spanish Annual Social Report, 2004. Anuario Social de España. Barcelona, Fundación "La Caixa”, 459 pp.

Strand BH, Kunst A, Huisman M, Menvielle G, Glickman M, Bopp M, Borrell C, Borgan JK, Costa G, Deboosere P, Regidor E, Valkonen T, Mackenbach JP, European Union Working Group on Socioeconomic Inequalities in Health, 2007. The reversed social gradient; higher breast cancer mortality in the higher educated compared to the lower educated. A comparison of 11 European populations during the 1990s. Eur J Cancer 43, 1200-1207.

Vaneckova P, Beggs PJ, Jacobson CR, 2010. Spatial analysis of heat-related mortality among the elderly between 1993 and 2004 in Sydney, Australia. Soc Sci Med 70, 293-304.

World Bank, 1993. World development report 1993. Investing in Health. New York, USA. Oxford University Press. 